\title{
Uso do fixador esquelético externo Tipo II para osteossíntese de tibiotarso em galinhas da raça Plymouth Rock Branca: modelo experimental para uso em aves selvagens ${ }^{1}$
}

\author{
Juliano B. De Conti ${ }^{2 *}$, João E.W. Schossler ${ }^{3}$, Marcelo M. Alievi ${ }^{4}$, Adamas T. Bonfada ${ }^{5}$, \\ Deise Novosad ${ }^{6}$, Danieli Silva ${ }^{6}$ e José R. Pachaly ${ }^{7}$
}

\begin{abstract}
De Conti J.B., Schossler J.E.W., Alievi M.M., Bonfada A.T., Novosad D., Silva D. \& Pachaly J.R. 2007. [Use of Type II external skeletal fixator for tibiotarsus osteosynthesis in White Plymouth Rock chickens: An experimental model for using in wild birds.] Uso de fixador esquelético externo Tipo II para osteossíntese de tibiotarso em galinhas da raça Plymouth Rock Branca: modelo experimental para uso em aves selvagens. Pesquisa Veterinária Brasileira 27(5):199-204. Curso de Medicina Veterinária, Universidade Estadual de Maringá, Estrada da Paca s/n, Zona Rural, Umuarama, PR 87502-000, Brazil. E-mail: julianodeconti@yahoo.com.br

The efficiency of the Type II external skeletal fixator for the treatment of tibiotarsus fracture in eight adult White Plymouth Rock chickens was evaluated. The individuals were premedicated with morphine sulfate and anesthetized with halothane, and submitted to a diaphysary osteotomy in the left tibiotarsus, performed with an oscillatory saw. Four Kirschner wires were inserted through the bone cortices, being two proximally and two distally to the fracture. After the fracture reduction the ends of both proximal and distal wires were twisted in distal or proximal direction, respectively, being the wires connected by two bars of autopolymerizing acrylic resin, in the external lateral and medial faces of the limb. The return to full capability to use the member was observed in $20.00 \pm 7.09$ days, and the bone healing occurred in 35.12 \pm 8.72 days. The results of this study showed that open reduction and use of Type II external skeletal fixator is an effective method for the treatment of tibiotarsus fractures in White Plymouth Rock chickens.
\end{abstract}

INDEX TERMS: Fracture, birds, tibiotarsus, orthopedics, external fixator Type II.

RESUMO.- Foi avaliada a eficiência do fixador esquelético externo Tipo II para o tratamento de fratura de tibiotarso em oito galinhas adultas da raça Plymouth Rock Branca. As aves foram pré-medicadas com sulfato de morfina e anestesiadas

\footnotetext{
${ }^{1}$ Recebido em 24 de janeiro de 2007.

Aceito para publicação em 12 de março de 2007.

2 Curso de Medicina Veterinária, Universidade Estadual de Maringá (UEM), Estrada da Paca s/no., Umuarama, Paraná, PR 87502-000, Brazil. *Autor para correspondência: julianodeconti@yahoo.com.br

${ }^{3}$ Curso de Medicina Veterinária, Universidade Federal de Santa Maria (UFSM), Avenida Roraima 1000, Cidade Universitária, Bairro Camobi, Santa Maria, RS 97105-900.

${ }^{4}$ Curso de Medicina Veterinária, Universidade Federal do Rio Grande do Sul (UFRGS), Av. Paulo Gama 110, Porto Alegre, RS 90040-060.

${ }^{5}$ Mestrando em Cirurgia Veterinária, UFSM, Santa Maria, RS.

${ }^{6}$ Acadêmica do Curso de Medicina Veterinária da UFSM, Santa Maria, RS.

${ }^{7}$ Curso de Medicina Veterinária, Universidade Paranaense (UNIPAR), Praça Mascarenhas de Moraes s/n, Umuarama, PR 87502-210.
}

com halotano. Em seguida, foi realizada osteotomia na diáfise do tibiotarso esquerdo, por meio de serra oscilatória. Quatro pinos de Kirschner foram inseridos através das corticais ósseas, dois proximalmente e dois distalmente ao foco da fratura. Após a redução desta, as extremidades dos dois pinos proximais e distais foram torcidas em direção distal ou proximal, respectivamente, sendo os pinos conectados externamente por meio de duas barras de acrílico autopolimerizável, nas faces lateral e medial externa do membro. $\mathrm{O}$ retorno da plena capacidade de utilização do membro foi observado em


radiográfico, ocorreu em $35,12 \pm 8,72$ dias. Os resultados do experimento demonstraram que redução aberta e aplicação de fixador esquelético externo Tipo II é método efetivo para o tratamento de fraturas de tibiotarso em galinhas da raça Plymouth Rock Branca.

TERMOS DE INDEXAÇÃO: Fratura, aves, tibiotarso, ortopedia, fixador externo Tipo II. 


\section{INTRODUÇÃO}

Atualmente, no Brasil e no mundo, se observa grande interesse na preservação da vida selvagem, de forma geral, e significativa casuística referente a espécies não domésticas como animais de estimação, em clínicas e hospitais veterinários (Hall \& Clark 1987, Pachaly 2004), dentre elas, as aves.

Vários métodos e resultados têm sido relatados, no tratamento de fraturas de ossos longos em aves (Friedburg 1961, Bush 1977, Williams et al. 1987). Não existe método único de estabilização que seja ideal para tratamento de todas as fraturas, porém aquelas que ocorrem no terço médio da diáfise, na maioria das vezes, requerem tratamento cirúrgico, podendo ser utilizados diversos materiais, como pinos intramedulares e fixadores externos (Egger 1996, Rupley 1999).

Segundo Pead \& Carmichael (1989), os fixadores externos podem ser utilizados em ampla variedade de situações, possibilitando estabilização com pequena exposição cirúrgica e limitando a possibilidade de ocorrência de lesões transoperatórias. Além disso, são métodos menos onerosos e requerem pequena quantidade de equipamentos.

Diante dessas considerações, o objetivo deste trabalho foi empregar o fixador esquelético externo Tipo II no reparo de fraturas diafisárias de tibiotarso em galinhas da raça Plymouth Rock Branca, avaliando o tempo decorrido até a utilização funcional do membro e a cicatrização, identificada por imagem radiográfica da fratura, no período de permanência do fixador externo e até o $15^{\circ}$ dia após a retirada do mesmo.

Em aves, as fraturas se localizam mais comumente nos membros pélvicos, especialmente no tibiotarso, sendo facilmente diagnosticadas quando os pacientes são corretamente examinados, pois geralmente ocorre desvio do eixo ósseo e mobilidade anormal do membro fraturado (Arnall \& Keymer 1975).

É difícil definir o método adequado para redução de fraturas em aves, devido às variações de peso e tamanho dos animais, e aos diversos graus de complicação das fraturas (Friedburg 1961, Williams et al. 1987).

Segundo Williams et al. (1987) e MacCoy (1991), os objetivos do reparo das fraturas em aves são idênticos aos do reparo das fraturas em mamíferos. Assim, o primeiro deles é promover o correto alinhamento dos fragmentos ósseos e a manutenção da função biomecânica normal e, o segundo, proporcionar rígida estabilização da fratura. Tal estabilização promove rápida formação de calo ósseo, além de desenvolvimento dos vasos sanguíneos, minimizando os danos às estruturas adjacentes e inibindo o risco de lesões em nervos, vasos ou músculos, provocadas pelos fragmentos ósseos instáveis. Assim, possibilita-se o uso do membro fraturado durante a reparação do trauma, diminuindo com isso o tempo de cicatrização (Bush 1977).

De acordo com Williams et al. (1987), fatores que devem ser levados em conta na seleção entre os vários métodos de tratamento no reparo de fraturas em aves incluem custo do material, tempo necessário para o procedimento, facilidade de aplicação e nível de demanda funcional entre as diversas espécies e indivíduos.

Os aparelhos de fixação externa promovem bom alinhamento anatômico e imobilização adequada das extremida- des fraturadas, resultando em cicatrização rápida, uso precoce do membro locomotor e mínima formação de calo ósseo (Bush 1977, Williams et al. 1987, Pead \& Carmichael 1989).

Egger (1993) classificou os aparelhos de fixação externa em três tipos: a) Tipo I ou "meios pinos", aparelhos nos quais os pinos atravessam as duas corticais do osso, mas não se insinuam no lado oposto do membro, sendo fixados unilateralmente por uma barra de metal ou de acrílico; b) Tipo II ou "pinos inteiros", aparelhos nos quais os pinos, além de atravessar as duas corticais ósseas, atravessam os tecidos moles do lado oposto, sendo fixados bilateralmente por barras de metal ou acrílico; c) Tipo III, aparelhos constituídos por associação dos tipos anteriores, tomando forma tridimensional.

Segundo Levitt (1989), o aparelho de fixação externa deve permitir o uso relativamente normal do membro fraturado durante o período de convalescença, de forma a evitar atrofia muscular e proporcionar maior rapidez no retorno do membro à sua função. $\mathrm{O}$ mesmo autor cita que o aparelho de fixação esquelética externa Tipo II é ideal para o tratamento de fraturas de tibiotarso em aves, visto que devido às corticais ósseas serem muito delgadas, ao se usar o fixador esquelético externo tipo I tende a ocorrer afrouxamento dos pinos e falha na fixação.

Williams et al. (1987) e Wissman (1999) relataram que as aves têm cicatrização óssea mais rápida que os mamíferos, sendo que a estabilização de fraturas leva duas a três semanas, embora neste período o calo ósseo ainda não seja perfeitamente visível ao exame radiográfico.

West et al. (1996), em estudo histológico em pombos, observaram que a formação de calo ósseo periosteal é superior, temporalmente, à formação de calo endosteal. Os autores relataram a formação de extenso calo cartilaginoso duas semanas após a fratura. Já Alievi (2000) e Gaiga \& Schossler (2002) verificaram que, em função desse calo cartilaginoso, os sinais clínicos de consolidação óssea acontecem antes dos sinais radiográficos.

A complicação mais freqüentemente observada, ao se utilizar fixadores esqueléticos externos, é a lise óssea ao redor dos pinos, radiograficamente visível a partir do trigésimo dia após a colocação do aparelho (Johnson et al. 1989).

\section{MATERIAL E MÉTODOS}

Foram utilizadas oito galinhas da raça Plymouth Rock Branca, com idade de 10-12 meses e peso médio de $2,0 \mathrm{~kg}$. Os animais foram alojados no Biotério Central da UFSM, em gaiolas individuais de $1,0 \mathrm{~m}^{2}$, onde permaneceram por 15 dias para adaptação ao local e à alimentação.

Para o procedimento cirúrgico, após seis horas de jejum, cada ave era encaminhada ao Laboratório de Cirurgia Experimental da UFSM, recebendo sulfato de morfina ${ }^{8}$ como pré-medicação, na dose de $4,0 \mathrm{mg} / \mathrm{kg}$, por via intramuscular. A seguir, era anestesiada com halotano ${ }^{9}$, inicialmente com ajuda de máscara, sendo que após a perda do reflexo laringo-traqueal se efetuava a colocação de sonda orotraqueal. Uma vez anestesiado o paciente, iniciava-se monitori-

\footnotetext{
${ }^{8}$ Dimorf: Cristalia, Porto Alegre, RS.

${ }^{9}$ Halotano: Hoechst do Brasil, Química e Farmacêutica S.A., Suzano, SP.
} 
zação de pressão arterial por meio de Doppler posicionado na região da artéria carótida.

As penas da região tibiotársica do membro esquerdo eram removidas manualmente, por tração, e o campo operatório submetido a antissepsia com gluconato de clorexidina ${ }^{10}$ a $4,0 \%$. Como medida profilática, cada ave recebia $20,0 \mathrm{mg} / \mathrm{kg}$ de ampicilina sódica ${ }^{11}$, por via intramuscular, 30 minutos antes do procedimento cirúrgico.

Com o animal em decúbito dorsal, efetuava-se incisão cutânea com bisturi, na porção crânio-medial do tibiotarso esquerdo. A seguir, o músculo fibular longo e a porção interna do músculo gastrocnêmio eram rebatidos no sentido cranial e caudal, respectivamente (Fig.1 e 2). Com tais procedimentos, expunha-se a região diafisária tibiotarsica, permitindo assim a realização de osteotomia transversa, empregando-se uma serra oscilatória ${ }^{12}$ (Fig.3).

Imediatamente após a osteotomia, efetuava-se a osteossíntese, implantando-se um fixador esquelético externo Tipo II. Este fixador

${ }^{10}$ Gluconato de Clorexidina 4\%: Vico Farma - Farmácia de Manipulação, Santa Maria, RS.

${ }^{11}$ Ampicilina Veterinária: Univet S.A., São Paulo, SP.

${ }^{12}$ Serra oscilatória Striker: Striker Instruments, Kalamazoo, Michigan, USA.

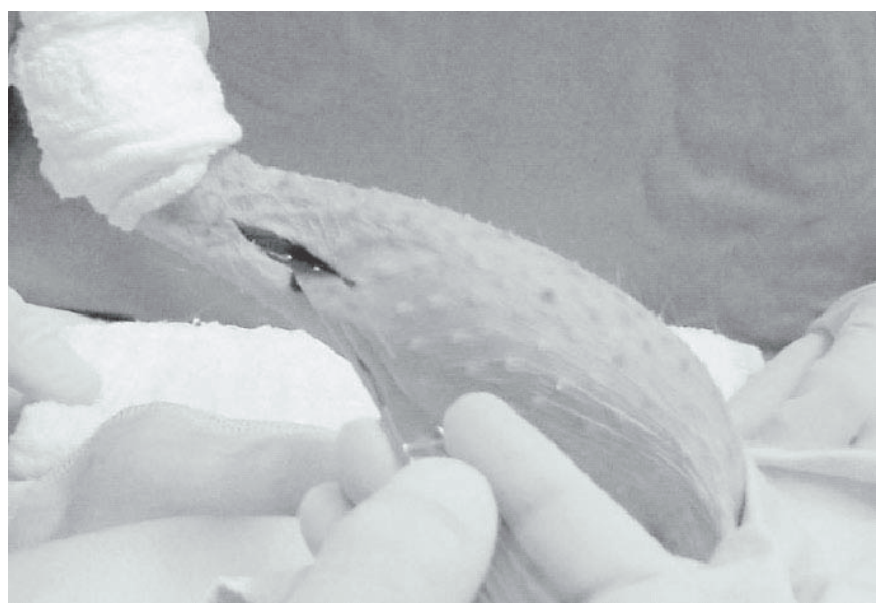

Fig.1. Incisão cutânea medial na região tibiotársica em galinha da raça Plymouth Rock Branca.

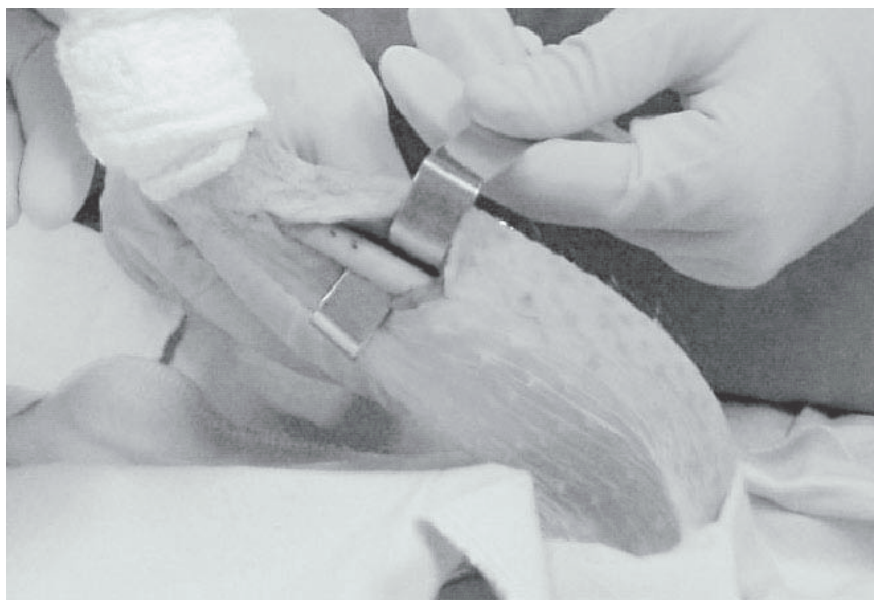

Fig.2. Exposição do terço médio do tibiotarso em galinha da raça Plymouth Rock Branca.

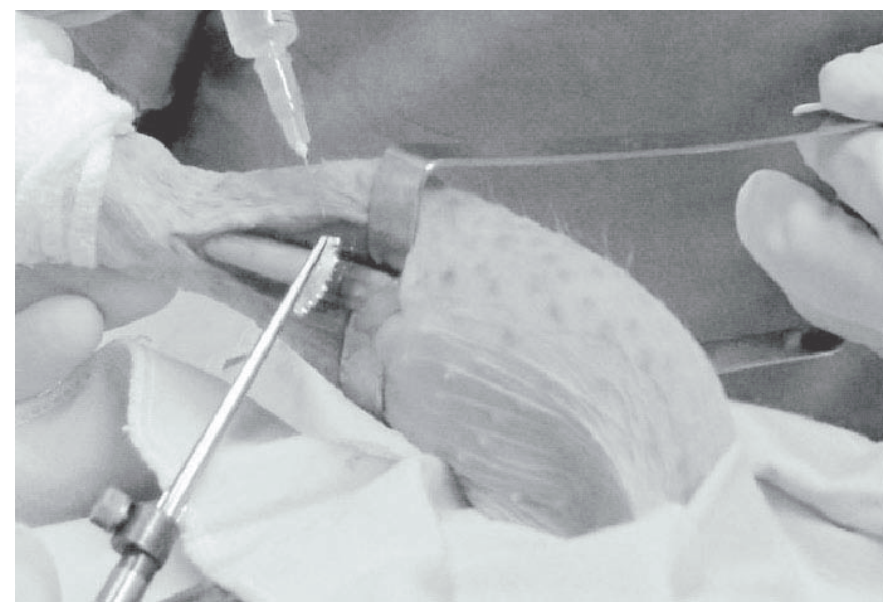

Fig.3. Osteotomia transversa do tibiotarso em galinha da raça Plymouth Rock Branca, empregando-se serra oscilatória.

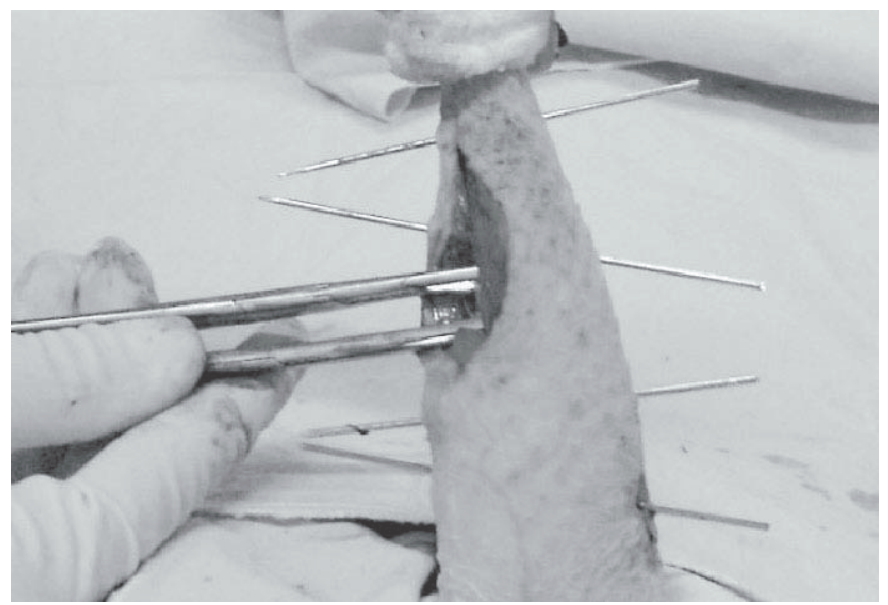

Fig.4. Inserção de dois pinos de Kirschner distais e dois proximais ao foco de fratura de tibiotarso, em 70 graus, em galinha da raça Plymouth Rock Branca.

externo era constituído por quatro pinos de Kirschner de 2,0 mm de diâmetro, sendo dois implantados proximal e dois distalmente à osteotomia, de forma que $\mathrm{o}$ ângulo menor formado entre o pino e o osso era de aproximadamente 70 graus. Os pinos foram inseridos pela face lateral do tibiotarso, utilizando uma parafusadeira elétrica, transfixando pele, musculatura e osso, sem qualquer dano iatrogênico. A seguir, e após suas extremidades serem em angulação de aproximadamente 90 graus, a fim de aproximá-las umas das outras, os pinos foram conectados externamente por duas barras de acrílico autopolimerizável ${ }^{13}$, uma na face lateral e outra na face medial da região tibiotársica do membro pélvico esquerdo (Fig.4 e 5). Após a colocação da barra lateral, e anteriormente à colocação da barra medial, efetuava-se a síntese do tecido subcutâneo, com categute cromado $^{14}$ 3-0 em pontos isolados simples (Fig.6), e da pele com mononáilon ${ }^{15}$ 3-0 em pontos isolados simples.

\footnotetext{
${ }^{13}$ Jet Acrílico: Artigos Odontológicos Clássicos, São Paulo, SP.

${ }^{14}$ Categute cromado: Sut Line Indústria e Comércio de Fios Cirúrgicos Ltda, Anápolis, GO.

${ }^{15}$ Nylipoint, Point Suture do Brasil, Fortaleza, CE.
} 


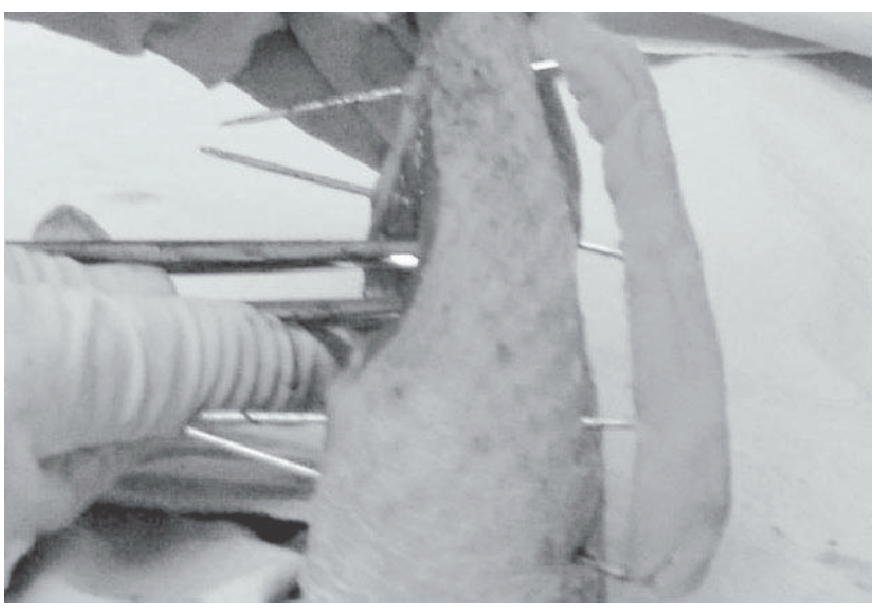

Fig.5. Barra de acrílico na face lateral do tibiotarso, conectada aos dois pinos de Kirschner distais e dois proximais ao foco de fratura de tibiotarso, em galinha da raça Plymouth Rock Branca.

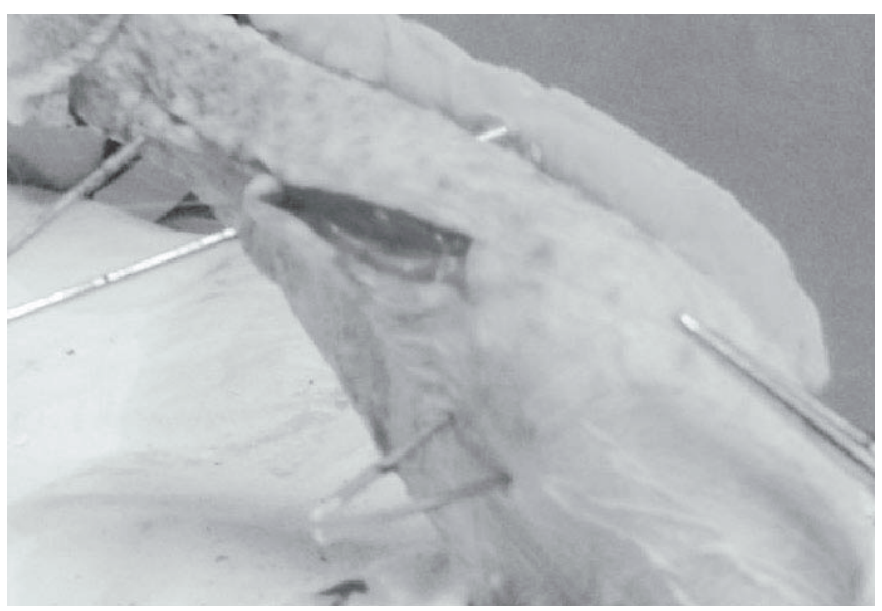

Fig.6. Síntese do tecido subcutâneo após osteossíntese de tibiotarso com fixador externo Tipo II, em galinha da raça Plymouth Rock Branca, utilizando categute cromado 3-0, com pontos isolados simples.

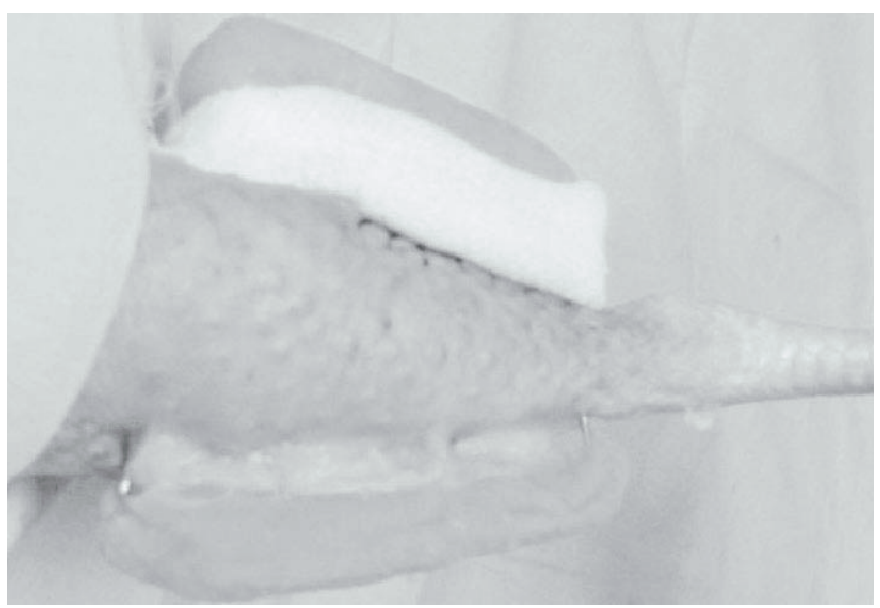

Fig.7. Curativo local com nitrofurazona e gaze envolvendo a pele e a inserção dos pinos, após osteossíntese de tibiotarso com fixador externo Tipo II, em galinha da raça Plymouth Rock Branca.
Quadro 1. Características radiográficas, em graus, utilizadas para avaliação pós-operatória de galinhas da raça Plymouth Rock Branca submetidas a osteossíntese de tibiotarso com fixador esquelético externo Tipo II

\begin{tabular}{cl}
\hline Grau & \multicolumn{1}{c}{ Características } \\
\hline I & Presença da linha de fratura e ausência de qualquer alteração óssea. \\
II & $\begin{array}{l}\text { Presença da linha de fratura e aumento da radiopacidade junto ao } \\
\text { foco de fratura. }\end{array}$ \\
III & $\begin{array}{l}\text { Presença da linha de fratura, aumento da radiopacidade junto ao } \\
\text { foco de fratura, reação periosteal e presença de calo ósseo. }\end{array}$ \\
IV Ausência da linha da fratura, aumento da radiopacidade junto ao \\
foco de fratura, reação periosteal e presença de calo ósseo.
\end{tabular}

Quadro 2. Características da deambulação, em graus, para avaliação clínica pós-operatória de galinhas da raça Plymouth Rock Branca submetidas a osteossíntese de tibiotarso com fixador esquelético externo Tipo II

\begin{tabular}{cl}
\hline Grau & Características \\
\hline I & A ave é incapaz de se manter em estação. \\
II & A ave se mantém em estação, porém não apóia o membro operado. \\
III & A ave se mantém em estação e apóia o membro, porém não o utiliza. \\
IV & A ave deambula, usando o membro operado de forma claudicante. \\
V & A ave deambula, usando o membro operado sem qualquer restrição.
\end{tabular}

Após o ato cirúrgico, todos os animais receberam como terapia antiinflamatória, flunixin meglumine ${ }^{16}$, em doses calculadas por meio de extrapolação alométrica interespecífica, de acordo com o método proposto por Pachaly \& Brito (2001), utilizando como animal-modelo o cão doméstico. Esse medicamento foi administrado diariamente por via intramuscular, durante três dias.

No local da inserção dos pinos na pele e na ferida cirúrgica era aposto curativo de gaze estéril embebida em solução à base de nitrofurazona ${ }^{17}$ (Fig.7), sendo o fixador externo envolvido por atadura de crepom. Tais procedimentos foram realizados em dias alternados até o sétimo dia de pós-operatório, quando foram removidas as suturas cutâneas após a cicatrização per primam da pele, e a seguir a cada quatro dias até a cicatrização óssea, quando o fixador externo era removido.

Ao término da intervenção cirúrgica, era realizada avaliação radiográfica do membro operado, nas incidências antero-posterior e médio-lateral. 0 mesmo procedimento era realizado no $15^{\circ}$ dia de pós-operatório, e a seguir semanalmente, até a plena cicatrização óssea. Caso não houvesse consolidação óssea, as radiografias eram tomadas semanalmente até o $60^{\circ}$ dia de pós-operatório. A avaliação das características radiográficas foi feita de acordo com os parâmetros propostos por Alievi (2000), que constam do Quadro 1.

A cada dois dias após o procedimento cirúrgico, durante 60 dias, realizou-se a avaliação da capacidade das aves em utilizar do membro operado, tendo como referência os parâmetros apresentados no Quadro 2, também propostos por Alievi (2000).

Quando da confirmação radiográfica da cicatrização óssea, cada ave era anestesiada pela associação de cloridrato de xilazina ${ }^{18} \mathrm{e}$ cloridrato de cetamina ${ }^{19}$, em doses de $3,0 \mathrm{mg} / \mathrm{kg}$ e $60,0 \mathrm{mg} / \mathrm{kg}$, respectivamente, por via intramuscular. $\mathrm{O}$ aparelho de fixação externa

\footnotetext{
16 Banamine: Shering-Plough Veterinária. Jacarepaguá, RJ.

17 Nitrofurazona: IFAL Indústria e Comércio de Produtos Farmacêuticos, Camaquã, RS.

18 Coopazine: Mallinckrodt Veterinária Ltda, Cotia, SP.

${ }^{19}$ Francotar: Virbac do Brasil, São Paulo, SP.
} 
era removido com a ajuda de alicate ortopédico, respeitando-se os princípios de assepsia e antissepsia cirúrgica. Após a remoção do fixador externo, as aves operadas foram avaliadas por mais 15 dias.

A análise estatística foi realizada por análise de variância, utilizando-se o teste F, pela aplicação do programa estatístico SAEG 2000 UFV.

\section{RESULTADOS}

O acesso cirúrgico medial ao tibiotarso possibilitou boa exposição da diáfise óssea, facilitando a produção da osteotomia e a redução da fratura. Contudo, em um dos animais ocorreu fratura oblíqua, no momento da osteotomia, provavelmente em função da cortical ser muito delgada e quebradiça, sem que isso influenciasse a cicatrização óssea, e tampouco o uso do membro. Apesar das corticais ósseas serem delgadas e muito frágeis, não se observaram fraturas de tibiotarso, nas demais aves, causadas pelos pinos, no momento da transfixação.

A técnica utilizada para osteossíntese promoveu boa aposição dos fragmentos ósseos e alinhamento satisfatório da fratura, sendo que a colocação de dois pinos proximais e dois pinos distais ao foco da fratura se mostrou eficiente na redução da mesma.

Na avaliação radiográfica, 15 dias após a osteossíntese, já era visível aumento da radiopacidade junto ao foco de fratura, porém com a presença da linha de fratura. Transcorridos 22 dias, $62,5 \%$ dos pacientes apresentavam presença da linha de fratura, aumento da radiopacidade junto ao foco de fratura, reação periosteal e presença de calo ósseo. Após 29 dias, 25\% dos pacientes já apresentavam calo ósseo exuberante e ausência da linha de fratura, e 36 dias após a osteossíntese, 75\% das aves apresentou calo ósseo exuberante e ausência da linha de fratura. Finalmente, aos 43 e 57 dias, respectivamente, as duas aves restantes $(25,0 \%)$ tiveram a fratura cicatrizada.

0 tempo médio para a identificação radiológica da cicatrização óssea foi de $35,12 \pm 8,72$ dias. Clinicamente, observou-se o restabelecimento da plena capacidade de deambula-

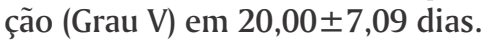

No período pós-operatório não foi observado qualquer sinal de secreção ou infecção nas áreas de inserção dos pinos. Entretanto, foi comum a todas as aves a ocorrência de hematoma nesta região, que perdurava em média 10 dias.

\section{DISCUSSÃO}

As galinhas da raça Plymouth Rock Branca se mostraram bom modelo experimental no que tange à aplicação da técnica cirúrgica proposta, visto que oferecem as mesmas características anatômicas de algumas aves selvagens. Entretanto, é importante lembrar que são aves domésticas, familiarizadas à presença humana e ao alojamento em gaiolas. Segundo observações pessoais, as aves selvagens, ao contrário, se estressam com muita facilidade, principalmente na presença humana, e se debatem no interior do recinto, sendo mais sujeitas a problemas como mobilidade no foco de fratura e, principalmente, deslocamento dos pinos.

De acordo com Williams et al. (1987) e Wissman (1999), as aves têm cicatrização óssea mais rápida que mamíferos, o que gera fraturas estáveis após duas a três semanas, embora nes- se período o calo ósseo ainda não seja bem visível, à avaliação radiológica. Adicionalmente, segundo Alievi (2000) e Gaiga \& Schossler (2003), em estudo histológico dos ossos, realizado em pombos, as aves não apresentam sinais radiográficos nítidos de calo ósseo nos primeiros 15 dias após a osteossíntese, o que se deve ao calo ósseo, nesse período, ser constituído por cartilagem hialina. Neste experimento, as aves apresentaram cicatrização óssea satisfatória em curto espaço de tempo, porém o calo ósseo só se tornou evidente, ao exame radiográfico, após a segunda semana de avaliação, corroborando as observações dos autores supracitados.

O emprego do fixador esquelético externo Tipo II permitiu alcançar os objetivos ideais no reparo das fraturas, os quais, segundo Williams et al. (1987) e MacCoy (1991), consistem em promover correto alinhamento dos fragmentos ósseos e manter as características biomecânicas normais do membro, bem como proporcionar rígida estabilização da fratura. Apesar das corticais ósseas das aves operadas serem delgadas e muito frágeis, os pinos, no momento da transfixação, não provocaram fraturas de tibiotarso.

Em trabalho utilizando tibiotarso e úmero de aves, Degernes et al. (1998) avaliaram a capacidade de fixação de várias configurações de pinos, concluindo que os pinos lisos não são indicados para confecção de aparelhos de fixação externa, visto não ter boa capacidade de fixação ao osso. Os resultados do presente estudo se opõem a esta informação, uma vez que os pinos lisos utilizados funcionaram perfeitamente na fixação óssea, provavelmente devido à angulação de $70^{\circ}$ em que foram inseridos, que aumentou a interface pino-osso, e à segurança proporcionada pelas duas barras conectoras, gerando fixação mais rígida.

\section{CONCLUSÕES}

O acesso cirúrgico medial ao tibiotarso permitiu ótima exposição da diáfise óssea, o que facilitou a produção da osteotomia e a redução da fratura. A técnica promoveu boa aposição dos fragmentos ósseos com alinhamento satisfatório da fratura, e o método de fixação esquelética externa proporcionou cicatrização óssea eficiente para tratamento de fraturas diafisárias de tibiotarso em galinhas da raça Plymouth Rock Branca. Adicionalmente, tem fácil aplicação, execução rápida e baixo custo.

\section{REFERÊNCIAS}

Alievi M.M. 2000. Redução fechada e fixação esquelética externa tipo I ou II para tratamento de fratura de tibiotarso em pombos domésticos (Columba livia). Dissertação de Mestrado em Cirurgia, Programa de Pós-Graduação em Medicina Veterinária, Universidade Federal de Santa Maria, RS. 38p.

Alievi M.M., Schossler J.E. \& Teixeira M. 1998. Osteossíntese de úmero em uma arara-canindé (Ara ararauna). Clín. Vet., São Paulo, 4(15):18-20.

Arnall L. \& Keymer I.F. 1975. Surgery, p.401-440. In: Idem (ed.), Bird Diseases. Baillière Tindall, London.

Bush M. 1977. External fixation of avian fractures. J. Am. Vet. Med. Assoc. 171(9):943-946.

Degernes L.A., Roe S.C. \& Abrams C.F. 1998. Holding power of different pin designs and pin insertion methods in avian cortical bone. Vet. Surgery 27(4):301-306. 
Egger E.L. 1966. Fixação esquelética externa, 1944-1966. In: Sllater D. (ed.), Manual de Cirurgia de Pequenos Animais. Vol.2. $2^{a}$ ed. Manole, São Paulo.

Friedburg K.M. 1961. Problems encountered in pet bird practice. Vet. Medicine 56:201-203.

Gaiga L.H. \& Schossler J.E. 2002. Osteossíntese de úmero por xenoenxerto ósseo preservado em mel em pombos domésticos (Columba livia). Ciência Rural, Santa Maria, 33(4):709-715.

Hall W. \& Clark K.W. 1987. Anestesia Veterinária. $8^{\underline{a}}$ ed. Manole, São Paulo, p.387-397.

Johnson A.L., Kneller S.K. \& Weigel R.M. 1989. Radial and tibial fracture repair with external skeletal fixation: effects of fracture type, reduction and complications on healing. Vet. Surgery 18(5):367-372.

Levitt L. 1989. Avian Orthopedic. Comp Cont. Educ. Pract. Vet. 11(8):899-929.

MacCoy D.M. 1991. General principles of the avian surgery. Comp. Cont. Educ. Pract. Vet. 13(6):989-992.
Pachaly J.R. \& Brito H.F.V. 2001. Interspecific allometric scaling, p.475-481. In: Fowler M.E. \& Cubas P.R. (ed.), Biology, Medicine and Surgery of South American Wild Animals. Iowa University Press, Ames.

Pachaly J.R. 2004. Medicina de répteis. Ciênc. Anim. Bras. 5(Supl.):36-38.

Pead M.J. \& Carmichael S. 1989. Treatment of the severely comminuted fracture in a rabbit using a Kirschner-Ehmer apparatus. J. Small Anim. Practice 30:579-582.

West P.G., Rowlnd, R.R. \& Budsberg S.C. 1996. Histomorphometric and angiographic analysis of bone healing in the humerus of pigeons. Am. J. Vet. Res. 57:1010-1015.

Williams R., Holland M. \& Milton J.L. 1987. A comparative study of treatment methods for long bone fractures. Companion Anim. Practice 1(4):48-55.

Wissman M.A. 1999. New tools, diagnostics aids in bone and beak repair in birds. Vet. Products News 11(6):44-45. 